石油技術協会誌 第 77 巻 第 1 号 （平成 24 年 1 月） $21 ２ 7$ 頁 Journal of the Japanese Association for Petroleum Technology

Vol. 77, No. 1 (Jan., 2012) pp. 21 27

\begin{tabular}{l}
\hline 講 演 \\
Lecture \\
\hline
\end{tabular}

音波検層波形記録を用いた地震波減衰解析*

\author{
鈴木 博之** $\cdot$ 松島 潤**
}

(Received September 20, 2011 : accepted January 13, 2012)

\title{
Estimation of seismic wave attenuation using sonic logging data
}

Hiroyuki Suzuki and Jun Matsushima

\begin{abstract}
Velocity is valuable information for finding the methane hydrate-bearing sediments. Only use of velocity for finding MH-bearing sediments is not enough and recent surveys have shown that the presence of $\mathrm{MH}$ in sediments has significant influence on seismic attenuation. Seismic attenuation can be conveniently separated into the intrinsic attenuation and apparent attenuation. Intrinsic attenuation is a measure of the amount of energy that is irreversibly removed from a seismic wave as it propagates through an inelastic medium due to energy conversion mechanisms. In contrast, apparent attenuation is due to elastic scattering from velocity and density heterogeneities, and commonly is referred to as scattering attenuation. The intrinsic attenuation is important in characterizing the physical properties of subsurface formations. However, it is generally difficult to distinguish between intrinsic attenuation and apparent attenuation.

The purpose of this study is to isolate the scattering attenuation and source-formation radiation coupling from the total attenuation derived from sonic waveform data obtained in MH-bearing sediments at the Nankai Trough area.

Firstly, we applied the median frequency shift method and spectral ratio method for sonic waveform data to estimate attenuation and compared their results. Results showed that at the Nankai trough, median frequency shift is better method for estimating attenuation.

Secondly, we estimated attenuation due to source-formation radiation coupling and scattering attenuation to isolate intrinsic attenuation. In this paper, we assume that the apparent attenuation includes only both the scattering attenuation and source-formation radiation coupling. Both source-formation radiation coupling and scattering attenuation showed moderate correlation at the MH-bearing layers, but the sizes of the heterogeneities showed that we need the data with higher resolution for precise estimation of scattering attenuation.
\end{abstract}

Keywords : methane hydrate, seismic attenuation, median frequency shift, source-formation radiation coupling, scattering attenuation

\section{1. 序論}

メタンハイドレート（以下 $\mathrm{MH}$ ）とは，水分子が低温高 圧化においてかご構造を作り，ガスを内包し固体化したも のを指し，永久凍土層の地層下，および日本近海の海底下 において存在が確認されている。佐藤ほか（1996）による 試算では，日本における資源量は天然ガス消費量で約 100 年分に相当するものであり, 非在来型のエネルギー資源と して近年注目されるものとなっている。しかし，この試算

*平成 23 年 6 月 8 日, 平成 23 年度石油技術協会春季講演会, 地質 - 探鉱 部門シンポジウム「岩石物性の理解は進んだか? 一最近のペトロフィ ジックスの現状と課題ー」で講演 This paper was presented at the 2011 JAPT Geology and Exploration symposium entitled "Petrophysics - Current applications and challenges for evaluation of rock properties" held in Tokyo, Japan, on June 8, 2011.

***東京大学大学院工学系研究科 School of Engineering, The University of Tokyo
では, 計算にハイドレート充填率やハイドレート安定領域 の層厚など多くの仮定や推定を含み, 現在においてもより 正確な資源量評価が必要とされている。

MH の探査は主に反射法地震探査によって行われ，近年 では BSR (bottom simulating reflector) の他にハイドレー 卜層の物理的特性を併せての探査手法に注目が集まってき た。ハイドレート層においては地震波速度が高くなること が知られており, 速度と飽和率の相関からハイドレート層 の探査が行われている。しかし，ハイドレート飽和率によ る速度上昇の程度は, ハイドレートの存在形式により異な るといつた課題もあり, 他の特性を用いての資源量評価も 研究されている。ハイドレート層においては減衰值も高く なることが検層波形から確認されており，その減衰情報を 基に資源量を評価できるかという点に関していまだ議論が 続いている (Guerin and Goldberg, 2002)。鈴木・松島（2009）

Copyright C 2012, JAPT 
では Frazer et al. (1997) による減衰值算出の方法を検証 し, 南海トラフにおける検層データから減衰值を算出, 飽 和率との関係を調べた。この研究においては, 地震波の減 衰には 1 つ種類のみが存在するとして計算を行つたが, Matsushima（2006）によれば，地震波減衰は内部減衰と その他の減衰に分離でき，鈴木・松島（2009）で算出した 減衰は内部減衰とその他の減衰を含む全減衰であった。内 部減衰以外の減衰は坑井内の環境などの影響を受けるた め, 減衰の有用性評価のためには内部減衰を分離する必要 があると考えられる。

本稿では鈴木・松島 (2009) に続き南海トラフの検層デー 夕を使用し，減衰の有用性評価を行った。減衰を median frequency shift, spectral ratio 法の 2 種類の方法により算出, 比較し, 次いで震源カップリング効果, 散乱減衰を考慮す ることで内部減衰を分離し，評価を行った。

\section{2. 音波検 層}

坑井内に測定器をおろし, 発振器から音波を発振, 地中 を通つて測定器へと戻ってきたものを受振器で測定する技 術を音波検層といい, 本研究で用いたシュルンベルジェ社 の DSI（Dipole Shear sonic Imager）では測定器の下部にモ ノポールおよびダイポール発振器が，また，上部には受振 器が 6 インチ間隔で 8 列, 図 1 のように設置されている。

音波検層では受振器のデータからスローネス（速度の逆 数）を計算することで伝播速度の測定が可能であり, 受振 器 - 発振器間の距離が近いため, ノイズの少ないデータが 取得できる。

また，波形デー夕をそのまま用いることにより，減衰值 を算出することが可能である。

本研究では減衰值の算出に 2 つの受振器のデータが必要 であるため, 最下部とその 1 つ上の受振器のデー夕を用い た。モノポールからは均質な波である縦波（P 波）が発振 され，P波速度の測定が可能である。ダイポールからは指 向性があり，孔壁がたわむたわみ波が発振される。本研究 では 500〜1000 [Hz] のダイポール波を横波（S 波）とみ

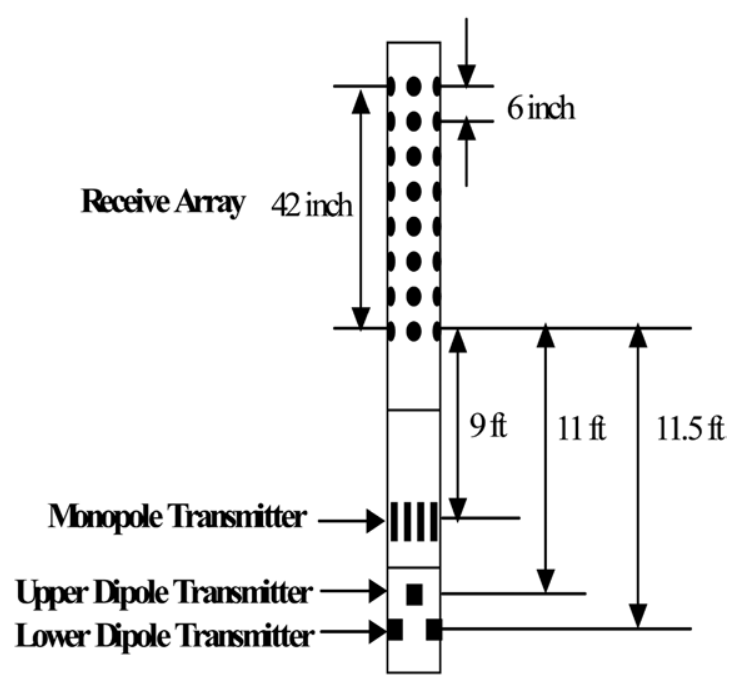

図 1 音波検層装置
なし， S 波速度の測定を行った。

\section{3. 減衰評価手法}

\section{1 減衰}

減衰とは，地震波が岩石中を伝播する際，振幅が減少す る基本的特性のことであり，伝播距離による減衰の大きさ は多くの場合, 指数関数により以下の式 (1) のようにモデ ル化される。

$$
A_{x}=A_{0}^{-a x} \quad \alpha=\frac{\pi f}{Q v}
$$

(1) 式において $x$ は伝播距離, $A_{0}$ は波の振幅, $f$ は周波数, $v$ は伝播速度, $Q$ は $\mathrm{Q}$ 值とよばれる減衰を示すパラメータ であり，逆数 $1 / Q$ が減衰值を表す。

減衰計算手法としては，一般に spectral ratio 法が用いら れている場合が多い。本稿では spectral ratio 法と median frequency shift という 2 種類の計算手法を用いて, 減衰值 を算出し，比較を行った。

\section{2 spectral ratio 法}

spectral ratio 法は，減衰算出において最も広く用いられ ている手法であり，2つの受振器間を波形が伝達した際の 波形の変化から減衰を求める。振幅スペクトルの対数が, 周波数軸でほぼ直線で減少していくことを基礎としてお り，地震波減衰は以下の式 (2)

$$
A\left(f, x_{2}\right)=B A\left(f, x_{1}\right) e^{-\pi f \Delta t / Q}
$$

で表される。 $A(f, x)$ は周波数 $f$, 深度 $x$ における振幅スぺ クトル, $\Delta t$ は 2 つの受振器間の地震波到着時間の差であ る。 $B$ は発振, 受振器の特性および幾何学的特性を含むパ ラメータであり，対数を取ることで以下の式 (3)

$$
\ln \left[\frac{A\left(f, x_{2}\right)}{A\left(f, x_{1}\right)}\right]=-\pi f \Delta t / Q+C
$$

に変換され，傾き $\pi \Delta t / Q$ から $Q$ を求めることができる。 上式において $C$ は発振, 受振器の特性, および幾何学的 特性を含んだ定数である。

\section{3 median frequency shift}

median frequency shift は周波数, 深度方向の平均を用い て, データに含まれるノイズを除去， $Q$ を計算する手法で ある (Frazer et al., 1997)。検層データをフーリエ変換した 深度 $z$ 毎, 一定周波数間隔の振幅スペクトル行列 $X$

$$
X(\omega, z, d)=B(\omega) E(\omega, z, d) e^{-\alpha d}
$$

から $Q$ 值を求めることができる。 $B$ は振幅スペクトル， $E$ はその他, 波に影響する理論的な効果, $d$ は伝播距離, $\alpha$ は減衰係数 $(\omega / 2 Q v)$ を表す。 median frequency shift で は, 上式から減衰を求める際に reference value として任意 の值らを導入する必要があり, 結果として算出される減 衰も reference value に依存する相対的な值となる。そのた 


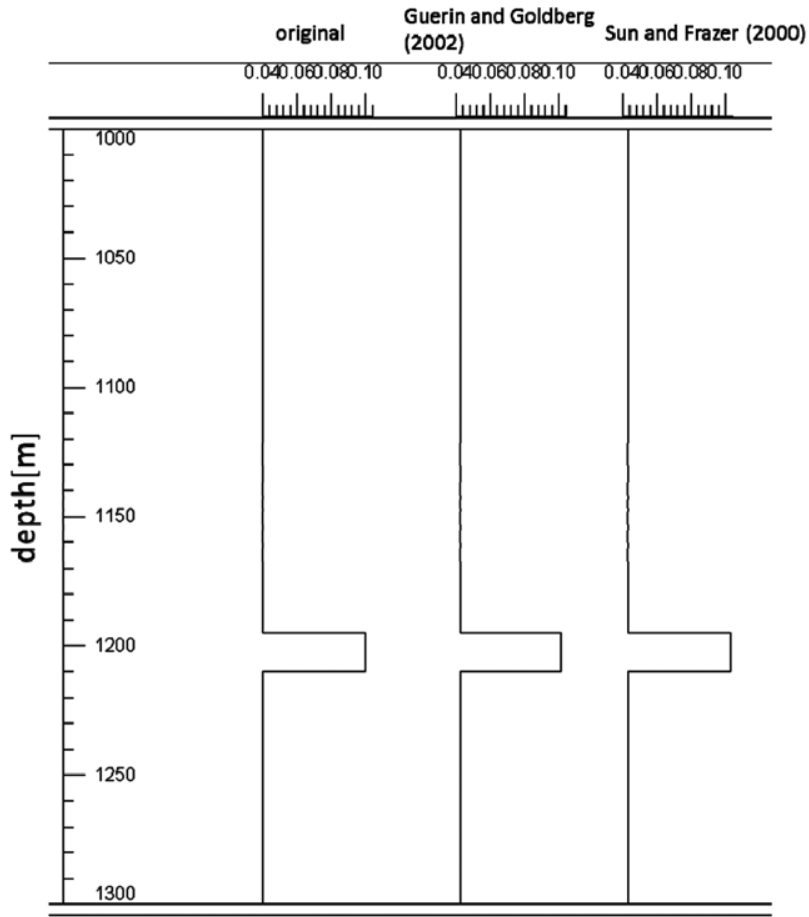

図 2 数值モデルの減衰ログ

左 : 設定值, 中央：Guerin and Goldberg (2002), 右：Sun and Frazer (2000)

め, この計算を補正する必要があり, Guerin and Goldberg （2002）やSun and Frazer（2000）がその補正方法を提唱 している。Guerin and Goldberg（2002）による手法は，相 対的な $Q$ 值を絶対的な值に補正するといつたものであり,

Sun and Frazer（2000）による手法は，任意に決定される 相対的な reference value を絶対的な值に補正するという手 法である。簡単な数值モデルを作成し性能評価を行ったと ころ，両方法とも十分補正が行えることを確認できたた め, 実データでは両方法により減衰を算出, 比較した。数 值モデルでは $1,000 １, 300[\mathrm{~m}]$ の深度で速度 $2,000[\mathrm{~m} / \mathrm{s}]$ の波を発生させ，1,195～1,210[m] での減衰值を 0.1 ，そ の他での減衰值を 0.04 に設定した。結果は図 2 に示す。 Guerin and Goldberg（2002） では 1,195〜1,210[m] での 減衰值を 0.102 , その他では 0.0426 と算出, Sun and Frazer (2000) ではそれぞれ $0.099 ， 0.0397$ と算出された。

\section{4. 実データを用いた検証}

\section{1 使用した実データ}

本稿では, 実データとして平成 11 年度基礎試錐「南海 トラフ」の 2 坑井 (PSW-1, PSW-3) で取得された DSI 検 層デー夕を使用した。周波数域として $\mathrm{P}$ 波では $10 \sim 20$ $[\mathrm{kHz}]$ を, S 波では $500 \sim 1,000[\mathrm{~Hz}]$ を用いている。また, 地震波にはモノポールでは $250[\mu \mathrm{s}]$, ダイポールでは 2 [ms] の密幅で hamming window を掛け合わせ, 波形の切 出しを行った。なお, PSW-1 では 1,215〜 1,221[m]，およ び 1,237〜1,244 [m] で P 波速度が正しく取得できていな かったため, Takayama et al. (2004) にしたがい, 該当深
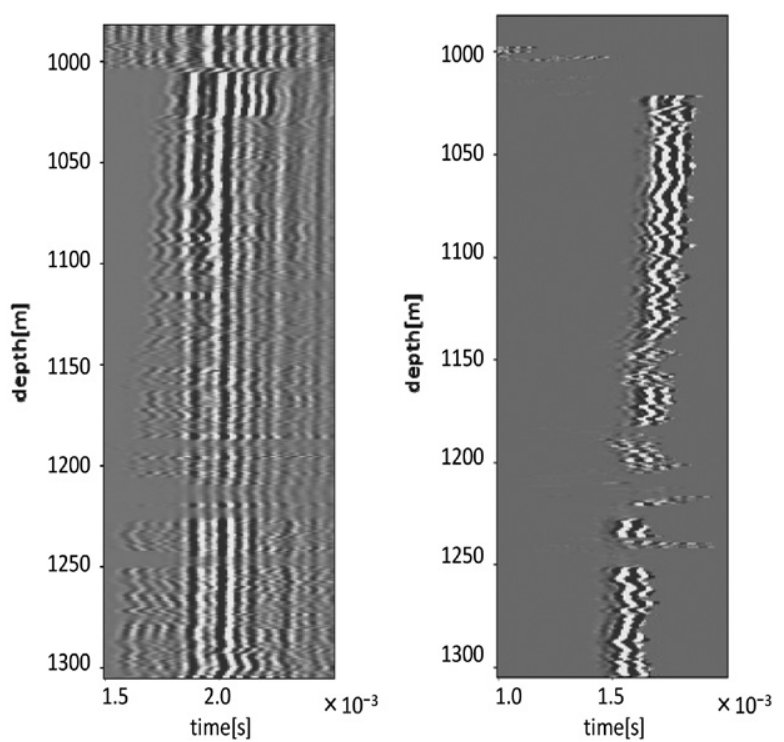

図 3 PSW-1 における P 波波形ログ (右図 空関数適用後)

度の $\mathrm{P}$ 波速度を $1,600[\mathrm{~m} / \mathrm{s}]$ とした（図 3 )。

\section{2 median frequency shift による減衰算出}

第一に, median frequency shift 用いて PSW-1, PSW-3 における減衰を算出した。結果は次の図 4,5 に示す。図 のハイドレート飽和率の高い層（PSW-1 では 1,180〜 1,190 [m] および $1,200 〜 1,210[\mathrm{~m}]$, PSW-3 では $1,190 \sim 1,220[\mathrm{~m}])$ で飽和率と減衰との相関を調べたところ，相関係数は表 1 のようになった。表は Guerin and Goldberg（2002）によ る補正の場合の相関係数であるが, Guerin and Goldberg （2002）による補正と Sun and Frazer（2000）による補正で, 計算結果にほとんど差異はなかつた。

南海トラフでは $\mathrm{P}$ 波に比べ $\mathrm{S}$ 波減衰との相関が高い。 この值は Guerin and Goldberg（2002）が Mallik 2L-38 にお いて求めた相関係数と比べると小さい值であり, さらに Mallik 2L-38においては, P波の方が S 波に比べ相関が高い。 相関そのものに関しても南海トラフに比べ大きい理由の 1

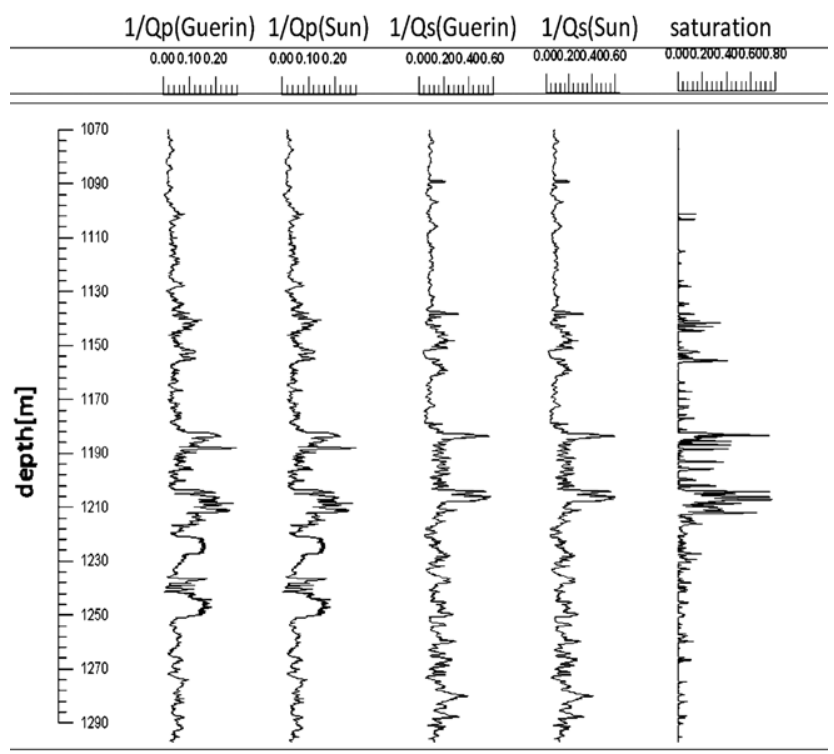

図 4 PSW-1 におけるハイドレート飽和率と減衰ログ 


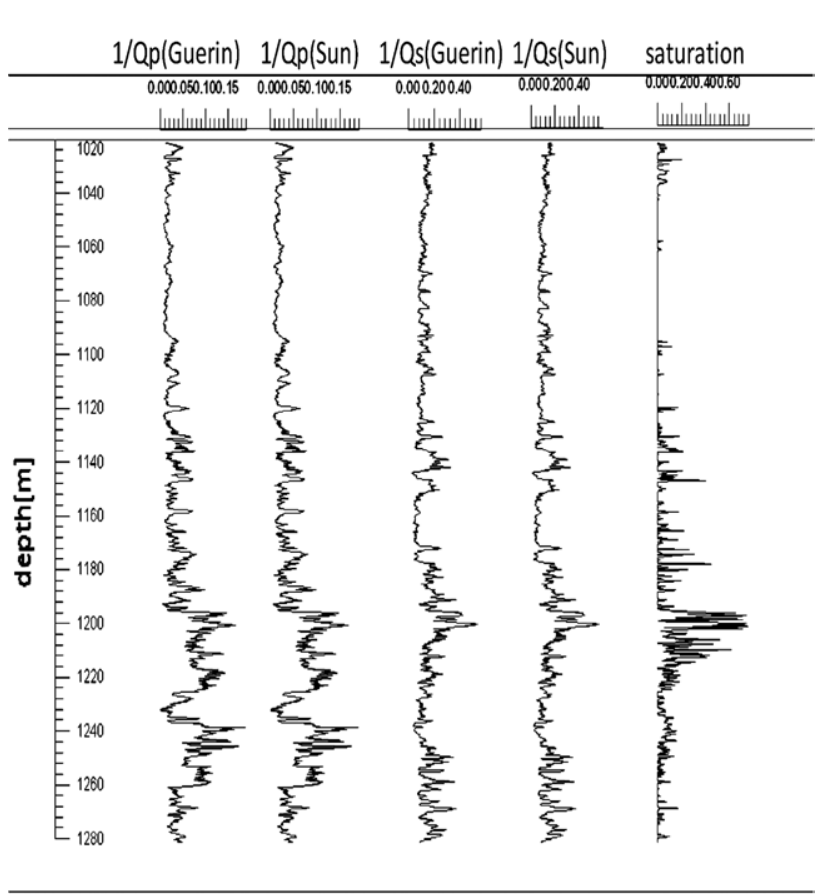

図 5 PSW-3 におけるハイドレート飽和率と減衰ログ

表 1 ハイドレート飽和率と減衰の相関係数

\begin{tabular}{|c|c|c|}
\hline & $\mathrm{P}$ 波 & $\mathrm{S}$ 波 \\
\hline PSW-1 & 0.57 & 0.70 \\
\hline PSW-3 & 0.53 & 0.68 \\
\hline
\end{tabular}

つとしては, Mallik2L-38 のハイドレート層は南海トラフ のハイドレート層と比べて層厚が大きく, 減衰との相関が よりはっきりと確認できたためと考えられる。

\section{3 spectral ratio 法との比較}

次に spectral ratio 法で減衰を算出し, 先に算出した median frequency shift によるものと比較した。PSW-1 にお ける P 波減衰との比較を行った。補正方法は Guerin and Goldberg（2002）による。

spectral ratio 法による減衰とハイドレート飽和率との 相関係数は 0.43 であり, 南海トラフにおいては median frequency shiftがより高い相関を示した。spectral ratio 法 による計算結果は不安定で, 坑井の変化やパラメータの変 化といつた影響を受けやすく, ノイズが入りやすい（Sams and Goldberg, 1990)。そのため, 減衰計算の手法としては median frequency shift の方が, spectral ratio 法と比べ優れ ていると考えられる。

\section{5. 内部減衰の抽出}

ここまでに, median frequency shiftにより音波検層波形 データから減衰を算出した。しかし, ここまでに求めた減 衰は地震波の内部減衰に加え, 震源カップリングや散乱効 果による減衰などが含まれた全減衰であり, 地震波の減衰 特性をより精確に調査するためには, 内部減衰を抽出し, その特性調査が必要であると考えられる。

以下では, 全減衰に含まれる減衰を内部減衰の他に震源 カップリングによる減衰, 散乱効果による減衰と考え, 内

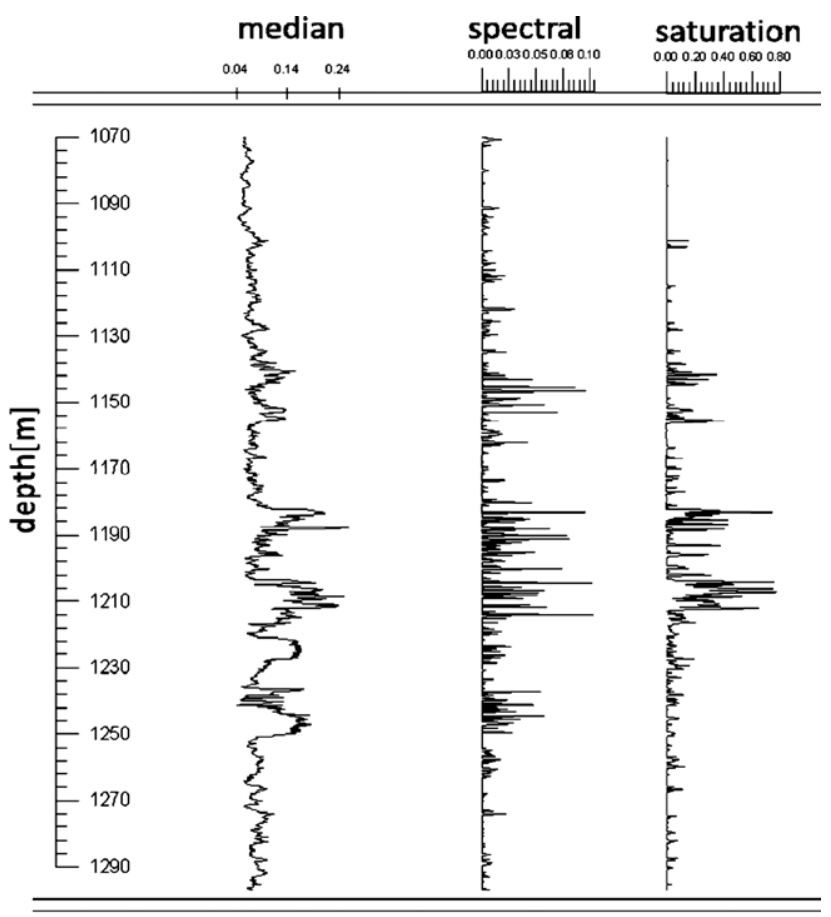

図 6 PSW-1 における減衰の比較（グラフ左は median frequency shift, グラフ中央は spectral ratio 法に よる減衰, グラフ右はハイドレート飽和率)

部減衰の抽出について検証した。

なお, 内部減衰の抽出については P 波の全減衰を用い た。S 波の減衰の方が南海トラフにおいては相関が高かっ たが，データの取得が $\mathrm{P}$ 波に比べ難しく，ノイズが入り やすいためである。さらに, 散乱減衰を求める際, 今回の 手法では初めに $\mathrm{P}$ 波の散乱減衰を算出するためである。

\section{1 source-formation radiation coupling}

$\mathrm{P}$ 波や $\mathrm{S}$ 波といつた波は発振点から発振した後, 坑井内 で放射するが，その放射パターンは坑井に加えられている 力などの環境により異なる。震源周りの坑井内環境は音波 検層波形デー夕を取得していく際, 連続的に変化するため, 周囲の環境への震源カップリング効果が振幅の減少に影響 する。これは median frequency shiftによって算出した減 衰に含まれていると考えられ, 内部減衰と分離することが 必要だと考えられる。

Lee（2006）によると, 震源カップリング効果は見掛け 減衰係数 $\alpha_{a}$ および伝播距離 $R$ を用いることで, 次の式 (5) のように表される。

$$
A \propto e^{-\alpha_{a} R}
$$

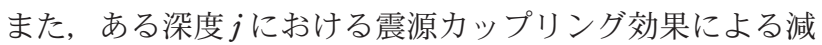
衰 $Q_{a, j}^{-1}$ は速度 $V$ を用いて次の式 (6), （7）で表すことがで きる。

$$
\begin{aligned}
& Q_{a, j}^{-1} \propto V_{j} \log \left(A_{c, j}\right) \\
& Q_{a, j}^{-1}=Q_{a, 1}^{-1} \frac{V_{j} \log \left(G_{j} C\right)}{V_{j} \log C}
\end{aligned}
$$

$G$ は正規化された振幅であり, $C$ により元の振幅の值へと 戻すことができる。Cは次の式 (8) のように計算すること 
ができる。 $f$ は周波数を示す。

$$
C=\exp \left(-Q_{a, 1}^{-1} f \pi R / V_{1}\right)
$$

本研究では，これらの式を用いて震源カップリング効果 を算出した。

今回の計算に当たっては, 深度の基準点 $(j=1)$ を求 めなければならない。その地点は今回用いたデー夕範囲で ハイドレート飽和率が 0 である地点のうち, 最も浅い点と した。

図 7 はPSW-1におけるP 波の減衰とカップリング効果 を比較したものである。震源カップリングの計算に用いた 周波数は $14[\mathrm{kHz}]$ とした。深度によりカップリング効果 の大きさは異なるが，地震波の全減衰においてカップリン グ効果による減衰が大きな割合を占める可能性が示唆され ている。

Lee（2006）では Mallik 5L-38 における震源カップリン グ効果を検証しているが，その結果は本研究により得られ た割合と比べて小さい。これについては先述の減衰算出の 結果と同様に，南海トラフにおけるハイドレート層の分布 が Mallik 5L-38 に比べて薄いことが影響している可能性も 原因の 1 つと考えられる。

\section{2 散乱効果による減衰}

地震波が地中を伝播する際，地中が不均質構造を取って いる場合には波が散乱し振幅が減少する。散乱効果による 滅衰であり，通常地中はさまざまな物体が混合しているた め不均質であるためこのような減衰が生じる。散乱減衰は より正確に減衰值を求める際に, 内部減衰と分離する必要 があると考えられる。散乱波は非干渉性であり，小規模の

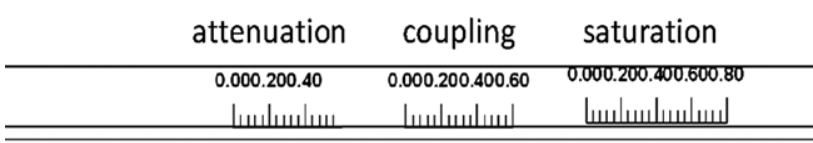

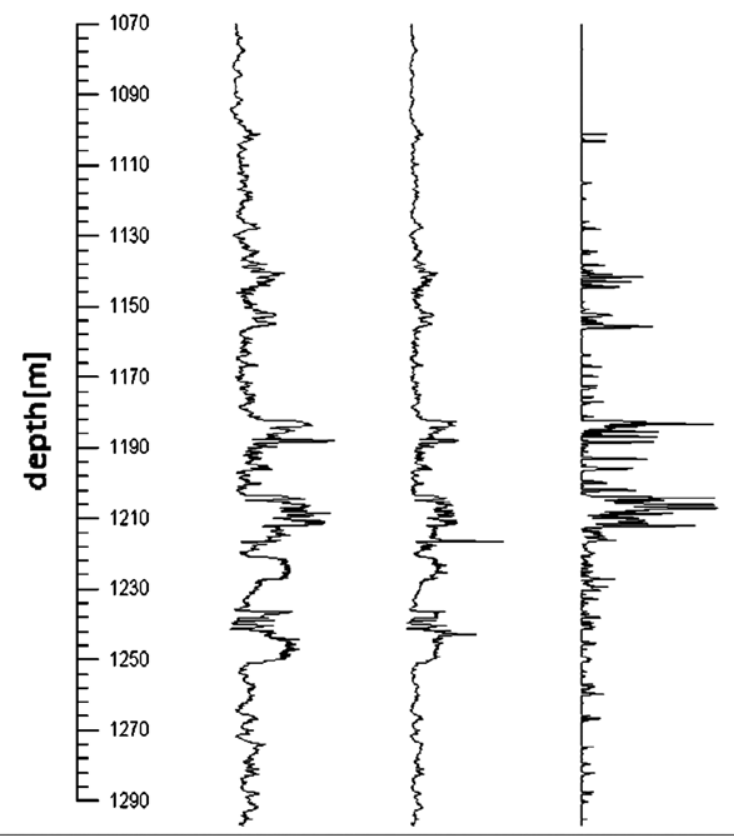

図 7 全減衰とカップリング効果による減衰の比較

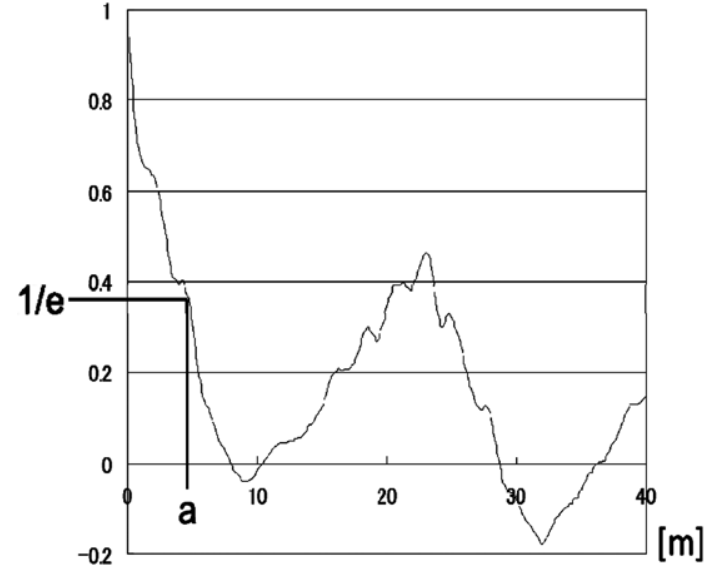

図 8 PSW-1 音波速度の自己相関

不均質性はランダムに分散していると推定されるため, 地震波の変動の統計的特性はこの不均質性の統計的特性 に関係していると考えられる（Matsushima and Nishizawa, 2010)。

\subsection{1 散乱減衰の分類}

Wu and Aki（1988）によると，音波速度の自己相関を用 いることで，散乱減衰の不均質性の計算が可能である。自 己相関の值が $1 / e$ になる点を $a$ とし, 波数 $k(k=2 \pi / \lambda)$ を掛け合わせた $k a$ の值により分類が可能である。

南海トラフにおいて計算したところ, $149<k a<297$ と なった。これは分類では forward scattering regime と呼ば れるものであり, この結果からすると, 今回の検層デー夕 では散乱減衰を正しく評価できない可能性が示唆される。 正しい散乱減衰の評価のためにはより分解能の高い検層 デー夕などを用いる必要があると考えられるが，今回は前 項までと同一のデータを用いて散乱減衰の評価を試みた。

\subsection{2 散乱効果の計算}

すべての減衰係数を $\alpha$, 見かけの減衰係数 $A$, 内部減 衰の係数 $I$ とすると, $\mathrm{P}$ 波, $\mathrm{S}$ 波において以下の関係が成 り立つ。

$$
\begin{aligned}
& \alpha(\omega)_{c}=A(\omega)_{c}+I(\omega)_{c} \\
& \alpha(\omega)_{s}=A(\omega)_{s}+I(\omega)_{s}
\end{aligned}
$$

ここで $C$ は P 波, $S$ は S 波, $\omega$ は周波数である。次に Lerche and Menke（1986）により, 以下の関係（経験式） が成り立つと仮定する。

$$
\begin{aligned}
& I(\omega)_{s}=\gamma I(\omega)_{c} \\
& A(\omega)_{s}=A(\lambda \omega)_{c} \\
& \quad\left(\gamma=\frac{3}{4} \lambda^{3}, \lambda=\frac{V_{p}}{V_{s}}, \lambda^{2} \geq 2\right)
\end{aligned}
$$

これらにより次の関係式(13)が導出され, 減衰係数 $I$ を 式(14)より求めることができる。

$$
\begin{aligned}
& I(\omega)_{c}-\gamma I\left(\frac{\omega}{\lambda}\right)_{c}=\alpha(\omega)_{c}-\alpha\left(\frac{\omega}{\lambda}\right)_{s} \equiv G(\omega) \\
& I(\omega)=-\sum_{p=0}^{\infty} G\left(\omega \lambda^{p+1}\right) \gamma^{-(p+1)}
\end{aligned}
$$


内部減衰は次の式（15）で表される。

$$
Q_{I}=\frac{\pi f}{I(\omega) v_{p}}
$$

\section{2 .3 実データでの計算}

南海トラフにおける音波検層波形デー夕を使用し，散乱 減衰について計算を行つた。

図 9 は P 波速度と $\mathrm{S}$ 波速度の比のログであり, 本研究 では，計算をする際に $\left(V_{p} / V_{s}\right)^{2} \geq 2$ を満たさない場所では

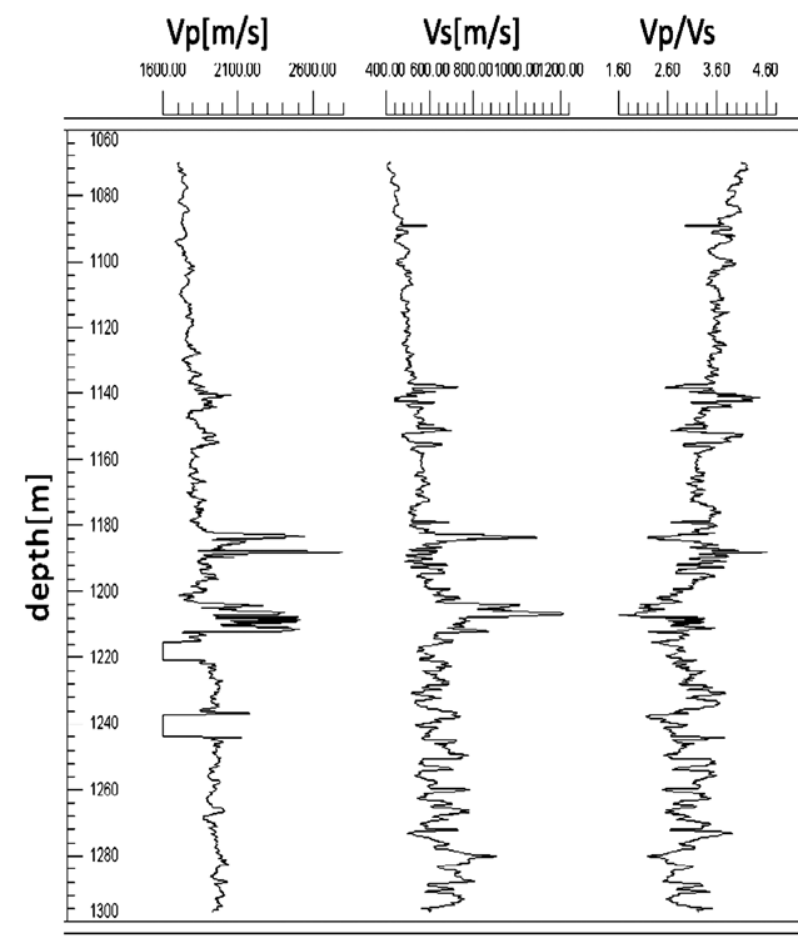

図 $9 \mathrm{P}$ 波速度と $\mathrm{S}$ 波速度の比
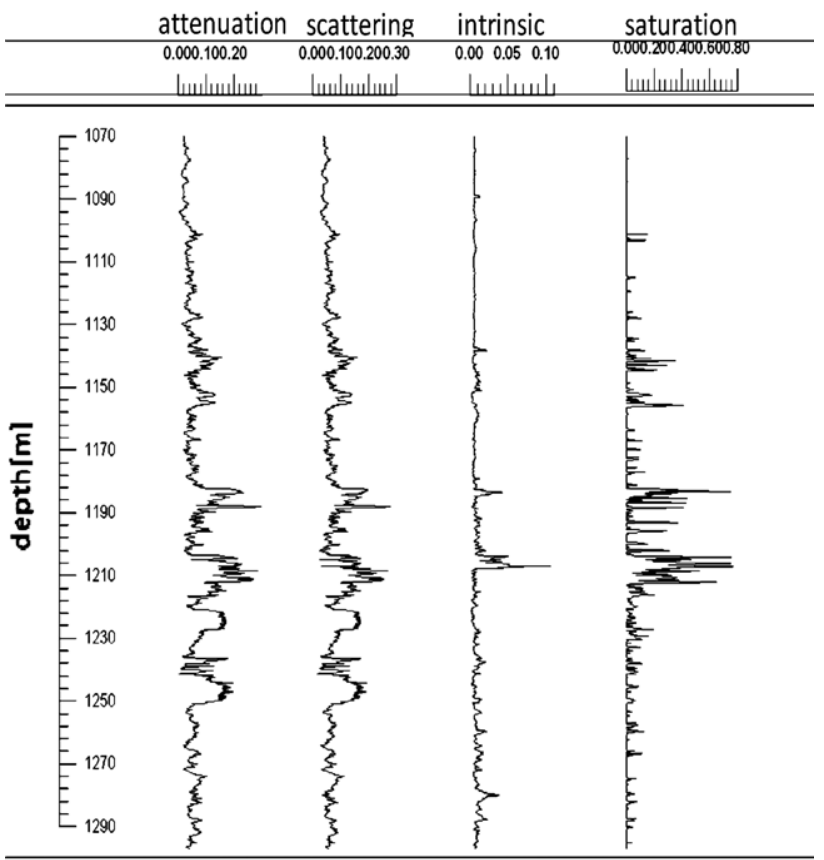

図 10 散乱減衰と全減衰および内部減衰に関するログ
$V_{p} / V_{S}=\sqrt{2}$ と置き換えて計算を行つた。

散乱減衰および全減衰, 内部減衰は図 10 で示される。 内部減衰は飽和率の高い層で大きな值となつており, 相関 が見受けられる。しかし，ここでの内部減衰は全減衰か ら散乱減衰のみを取り除いたものであり, 先に算出した source-formation radiation coupling をさらに取り除くと, 全減衰を超えてしまう層が存在している。原因としては, 検討で示唆されたように, 散乱減衰の不均質性により今回 用いたデータでは散乱減衰を正しく計算することができな いということが考えられる。

\section{6. まとめ}

本研究の結果によると, 南海トラフ検層波形デー夕を用 いての減衰計算手法としては median frequency shift が, spectral ratio 法に比べ優位性があると考えられる。また, 南海トラフにおいては, $\mathrm{P}$ 波よりも $\mathrm{S}$ 波が減衰計算により 適していると考えられる。これは Mallik 2L-38においては 逆の結果であり, ハイドレート層の層厚が結果に影響する と考えられる。

次に source-formation radiation coupling, 散乱減衰を評 価し, 内部減衰の分離を試みた。内部減衰はハイドレート 層で大きな值を取っており，ハイドレート飽和率との関係 が示唆される。しかし, 散乱減衰の不均質性が大きいため, 今回用いた音波検層ではデー夕の間隔が広すぎ，評価が正 しく行えない可能性が示唆された。今後, より分解能の高 い音波検層などを用いることによって正しく散乱減衰の評 価が行えると考えられる。

\section{謝 辞}

本研究を実施するにあたり, 下記資料を(独)石油天然力 ス・金属鉱物資源機構より借用しました。ここに記して感 謝の意を表します。

・平成 11 年度基礎試錐「南海トラフ」検層データ

\section{引用 文 献}

Frazer, L. N., Sun, X. H. and Wilkens, R. H., 1997 : Changes in attenuation with depth in an ocean carbonate section: Ocean Drilling Program sites 806 and 807, Ontong Java Plateau, J. Geophys. Res., 102, 2983-2997.

Guerin, G. and D. Goldberg., 2002 : Sonic waveform attenuation in gas hydrate-bearing sediments from the Mallik 2L-38 research well, Mackenzie Delta, Canada, J. Geophys. Res., 107 (B5), 2088, 10.1029/2001JB000556.

Lee, M. W., 2006: Is amplitude loss of sonic waveforms due to intrinsic attenuation or source coupling to the medium?, Sci. Invest. Rep, 2006-5120, 13 pp.

Lerche, I. and Menke, W., 1986: An inversion method for separating apparent and intrinsic attenuation in layered media, Geophys. J. R astr. Soc., 87, 333-347.

Matsushima, J., 2006 : Seismic wave attenuation in methane hydrate-bearing sediments: Vertical seismic profiling 
data from the Nankai Trough exploratory well offshore Tokai, central Japan, J. Geophys. Res., 111, B10101, 10.1029/2005JB004031.

Matsushima, J. and Nishizawa, O., 2010 : Difference image of seismic reflection sections with highly dense spatial sampling in random heterogeneous media, Journal of Seismic Exploration, 19, 279-301.

Sams, M. and Goldberg, D., 1990 : The validity of Q estimates from borehole data using spectral ratios, Geophysics, 55, 97-101.

佐藤幹夫・前川竜男・奥田義久， 1996 : 天然ガスハイドレー トのメタン量と資源量の推定, 地質雑, 102, 959-971.

Sun, X. and Frazer, L. N., 2000 : Shear wave attenuation profile from sonic dipole well-log data, Geophys. Res. Letters. $27,285-288$.

鈴木博之・松島 潤, 2009 : 音波検層波形デー夕を利用し たメタンハイドレート賦存層の減衰特性解析, 物理探査 学会第 120 回学術講演会論文集.

Takayama, T., Nishi, M., Yamamoto, H., Sanada, Y., Matsuda, S. and Uchida, T., 2004 : Occurrence of free-gas associated with methane-hydrate-bearing formations in the MITI Nankai Trough wells, offshore Tokai, Japan, Resour. Geol., $\mathbf{5 4}, 89-98$.

Wu, R., S. and Aki, K., 1988 : Introduction: Seismic wave scattering in three-dimensionally heterogeneous earth, Pure and Applied Geophysics. 128, 1-6, 10.1007/BF01772587. 